\title{
THE ADDITIVITY ANTINOCICEPTIVE INTERACTIONS BETWEEN DICLOFENAC AND THE DERRIS SCANDENS EXTRACT DRUG IN MICE
}

\author{
TADSANEE PUNJANON* \\ Department of Medical Science, Pharmacology and Toxicology Unit, Faculty of Science, Rangsit University, Pathum-thani 12000, Thailand. \\ Email: tadsanee@rsu.ac.th
}

Received: 02 September 2017, Revised and Accepted: 21 October 2017

\begin{abstract}
Objective: Combination therapy is a valid approach in pain treatment, in which a reduction of doses could reduce side effects and still achieve optimal analgesia. The objective was to determine the effects of coadministered diclofenac and the Derris scandens extract drug.

Methods: Acetic acid-induced abdominal constriction test in mice was used to determine the type of interaction between components. The effective dose that produced 50\% antinociception (ED50) was calculated from the log dose-response curves of fixed ratio combinations of diclofenac with the D. scandens extract drug. The $\mathrm{ED}_{50}$ was compared to the theoretical additive $\mathrm{ED}_{50}$ calculated from the $\mathrm{ED}_{50}$ of diclofenac and of the $D$. scandens extract
\end{abstract} drug alone.

Results: Diclofenac and the $D$. scandens extract drug dose-dependently and significantly reduced the abdominal writhing. The combination was the additive effect, the experimental $\mathrm{ED}_{50}$ being smaller than the theoretically calculated $\mathrm{ED}_{50^{\circ}}$. Interaction index of the combination was 0.89 .

Conclusion: The present study demonstrates the additivity antinociceptive interactions between diclofenac and the D. scandens extract drug and may be used as a combination analgesic in the treatment of pain conditions.

Keywords: Derris scandens, Diclofenac, Analgesic effect, Mouse, Abdominal constriction test.

(C) 2018 The Authors. Published by Innovare Academic Sciences Pvt Ltd. This is an open access article under the CC BY license (http://creativecommons. org/licenses/by/4. 0/) DOI: http://dx.doi.org/10.22159/ajpcr.2018.v11i1.22316

\section{INTRODUCTION}

Derris scandens (Roxb.) Benth, or Jewel Vine, known as Tao-WanPriang in Thai, is well-known the Asian medicinal plant. The stem of D. scandens has been used as active ingredient in the Thai traditional medicine recipes for pain treatment, for example, of osteoarthritis, joint diseases, musculoskeletal diseases, rheumatic diseases, and muscle tension [1]. The leaf and root extracts of $D$. scandens as well as the isolated flavonoids, ovaliflavanone, and lupinifolin showed antiinflammatory activity on carrageenan-induced paw edema in rats [2].

From the Thailand National List of Essential Medicines, the D. scandens extract is a drug developed from Thai medicinal plants. One formulated capsule contains $400 \mathrm{mg}$ of the $50 \%$ ethanol extract from the stem of D. scandens. Its indications are relieving pain in lower back pain and knee osteoarthritis [3-5]. Low back pain and knee osteoarthritis are frequently found in the elderly. The increasing of prevalence tendency is also found. Anti-inflammatory drugs, such as nonsteroidal antiinflammatory drugs (NSAIDs), are given to treat patients. However, the adverse effects of anti-inflammatory drugs are reported such as irritation and ulcers of the gastric and intestine system. The Thai Ministry of Public Health has the policy to support the research and development of herbal plants to be processed into high-quality goods and promote the use of the Thai herbs [6]. Therefore, the treatment effect of $D$. scandens is to replace or coadminister with other analgesic drugs by physicians and patients themselves.

The combination of analgesics of proven efficacy is a strategy intended to achieve one or more therapeutic goals [7]. Among the currently recommended analgesic products for arthritis-related pain, fixed-lowdose combination products hold promise for pain control because such products allow lower doses of individual agents resulting in decreased toxicity and acceptable efficacy due to the synergy between the individual drugs. Better evidence and recommendations are required to improve treatment of chronic arthritis-related pain [8].

The D. scandens extract drug shows interesting analgesic and antiinflammatory activities such as NSAIDs, and usage is increasing as replace or coadminister with another analgesic. Diclofenac is some of the most frequently used NSAIDs in clinical practice. There is no available information about the effect of the D. scandens extract drug on the analgesic interaction with diclofenac. In this study, we emphasized to study the analgesic interaction of the combination between diclofenac and the $D$. scandens extract drug in acetic acid-induced abdominal constriction test in mice and determine its type of analgesic interactions (synergism, additivity, or antagonism). The results from this study will provide the information of the combination between analgesic and alternative medicine. It is possible to suggest that the combinations of diclofenac and the $D$. scandens extract drug may be effective for the clinical treatment of pain.

\section{METHODS}

\section{Drugs and chemical reagents}

The commercial "GPO Thao-Wan-Priang Capsules," 50\% ethanolic extract from the stem of $D$. scandens produced by the Government Pharmaceutical Organization of Thailand was used. Aspirin was obtained from Merck, AG, Darmstadt, Germany. Diclofenac was obtained from the Community Pharmacy Public Company Limited, Thailand. Analytical grades of sodium chloride and acetic acid (Sigma, St. Louis, USA) were purchased locally. All other chemicals and solvents were of the highest grade commercially available.

Experimental animals

Adult male albino ICR mice (30-35 g) were obtained from the National Laboratory Animal Center, Mahidol University, Thailand. All mice were 
housed in the Faculty of Science, Rangsit University, Thailand, under standard environmental conditions of $22 \pm 1^{\circ} \mathrm{C}, 60-70 \%$ humidity, and $12 \mathrm{~h}$ light and $12 \mathrm{~h}$ dark cycle. All animals had free access to water and standard pellet laboratory animal diet and acclimatized for at least $l$ week before use. Before experiments began, the animals were deprived of food for $12 \mathrm{~h}$ and allowed to adapt to the laboratory for at least $2 \mathrm{~h}$ before testing. Each animal was used for one experiment only. The experiment was conducted in accordance with the Care of Laboratory Animals and Ethical Guidelines of National Research Council of Thailand. The experiment protocol was submitted and approved for ethical considerations by the Rangsit University Animal Ethics Committee (ID RSEC03/2558).

Acetic acid-induced abdominal constriction (writhing) test in mice This study was carried out using acetic acid-induced abdominal writhing reflex pain model $[9,10]$. Thirty-six mice were randomly divided into 6 groups (1-6, six animals per group, per treatment), fasted for $12 \mathrm{~h}$, and treated as follows: Group 1 (negative control group) received $0.1 \mathrm{ml} / 10 \mathrm{~g}$ body weight (bw), p.o. of distilled water, Group 2 (positive control group) received $50 \mathrm{mg} / \mathrm{kg}$ bw, p.o. of aspirin, and Groups 3, 4, 5 , and 6 received at each of at four doses of the D. scandens extract drug or diclofenac, respectively, using gastric gavage. Thirty minutes after the $D$. scandens extract drug or drug administration, $0.75 \% \mathrm{v} / \mathrm{v}$ glacial acetic acid $(0.1 \mathrm{ml} / 10 \mathrm{~g} \mathrm{bw})$ was administered intraperitoneally to all mice to induce abdominal contortions or writhings. The analgesic effect was assessed and recorded in each mouse by counting the incidences of writhes (arching of the back, development of tension in abdominal muscles, and elongation of the body in hind limb) for $30 \mathrm{~min}$

\section{Data analysis}

Numbers of writhing were presented as mean \pm standard error of the mean. The degree of antinociception was calculated as the percentage of inhibition of writhing using the rational formula.

The percentage of inhibition $=(\mathrm{Vc}-\mathrm{Vt}) / \mathrm{Vc} * 100$, where:

$\mathrm{Vc}=$ Mean number of writhing in control animals

$\mathrm{Vt}=$ Mean number of writhing in test animals

A least-squares linear regression analysis of the log dose-response curves allowed the calculation of the dose that produced $50 \%$ of antinociception $\left(\mathrm{ED}_{50}\right)$ for each drug. The analysis was performed using one-way analysis of variance (ANOVA), and the difference between the means was tested using post hoc least significant difference test. The value of $p<0.05$ was considered statistically significant.

A dose-response curve was also obtained by the oral coadministration of diclofenac with the $D$. scandens extract drug in fixed ratio combinations of fractions of their respective $\mathrm{ED}_{50}$ values: $1 / 2,1 / 4,1 / 8$, and 1/16 (ratio value given in Table 1). A dose-response curve and experimental $\mathrm{ED}_{50}$ for the combination of diclofenac and the D. scandens extract drug administered orally by gavage was also obtained with the same scheme. The interaction index was calculated as experimental $\mathrm{ED}_{50} /$ theoretical $\mathrm{ED}_{50}$. If the value is close to 1 , the interaction is additive. Values lower than 1 are an indication of the magnitude of supra-additive or synergistic interactions, and values higher than 1 correspond to subadditive or antagonistic interactions [11].

\section{RESULTS}

The result of the acetic acid-induced abdominal constriction test was summarized in Table 1 . The $D$. scandens extract drug, diclofenac, and the combination produced a significantly dose-dependent antinociceptive effect in the chemical viscerosomatic assay of the acetic acid abdominal constriction test compared with the control group. The $D$. scandens extract drug produced 5.5, 32.5, 68.4, and $90.2 \%$ of inhibition at the dose of $1,10,100$, and $1000 \mathrm{mg} / \mathrm{kg}$ bw, respectively, which was comparable to reference analgesic drug, aspirin $(78.3 \%$ of inhibition at $50 \mathrm{mg} / \mathrm{kg} \mathrm{bw}$ ). Diclofenac produced 3.7, 36.3, 49.5, 62.7, and $80.6 \%$ of inhibition at the dose of $1,10,50,100$, and $150 \mathrm{mg} / \mathrm{kg}$ bw, respectively $(\mathrm{p}<0.05, \mathrm{n}=6)$. The combination of diclofenac with the D. scandens extract drug produced $11.6,34.7,45.6$, and $79.9 \%$ of inhibition at the dose of 8.2 (1/16), 16.5 (1/8), $32.9(1 / 4)$, and $65.9(1 / 2) \mathrm{mg} / \mathrm{kg} \mathrm{bw}$, respectively.

The log dose-response curves for the antinociceptive effect of the $D$. scandens extract drug, diclofenac, and the combination were obtained using at least six animals at each of at least four doses as shown in Fig. 1. A least-squares linear regression analysis of the log doseresponse curves allowed the calculation of the dose that produced $50 \%$ of antinociception effective dose $50 \%\left(\mathrm{ED}_{50}\right)$ which were $35.5,30.4$, and $29.2 \mathrm{mg} / \mathrm{kg}$ bw, respectively.

The antinociceptive activity of the oral coadministration of fixed ratio combinations of $\mathrm{ED}_{50}$ fractions of diclofenac with the D. scandens extract drug was assessed by calculating the $\mathrm{ED}_{50}$ of the mixtures from the corresponding dose-response curves. The additive was present when the drug combination was administered orally. Table 2 represented the theoretical additive and the experimental observed $\mathrm{ED}_{50}$ values of the combinations which were 32.9 and $29.2 \mathrm{mg} / \mathrm{kg}$ bw, respectively. The interaction index of the combination was 0.89 .

\section{DISCUSSION}

As the D. scandens extract drug shows interesting analgesic and antiinflammatory activities such as NSAIDs and usage is increasing as replace or coadminister with another analgesic. In accordance with the medical uses of the $D$. scandens extract, the present study was carried out to evaluate the interaction of antinociceptive effect between diclofenac and the $D$. scandens extract drug. The major finding of the current study was the demonstration, for the first time to best of our knowledge, that the combination showed the additivity analgesic interaction in the chemical viscerosomatic assay of the acetic acid abdominal constriction test. This model is a pain-state model using chemical stimuli, which both central and peripheral analgesics are detected. A good relationship exists between the potencies of analgesics in writhing assays and their clinical potencies in this model. It has been used by many investigators and can be recommended as a simple screening method $[12,13]$.

The combination tested showed an additivity interaction with interaction index at 0.89 . The reduction of doses at 5.2 and $6.0 \%$ of diclofenac and the $D$. scandens extract drug in combination, respectively, compared with $\mathrm{ED}_{50}$ of the single drugs. However, in the previous study,

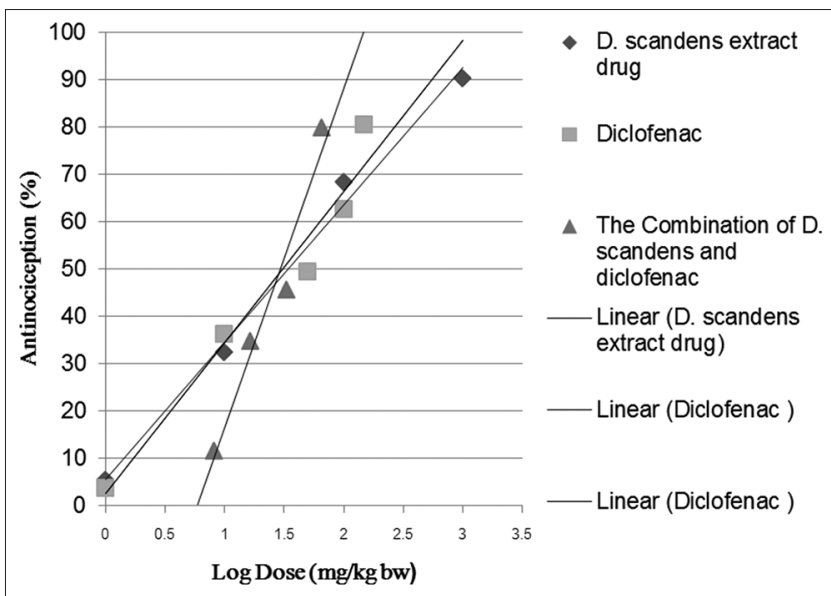

Fig. 1: Log dose-response curves for the antinociception induced by the oral administration of the Derris scandens extract drug, diclofenac, and the combination determined from acetic acidinduced abdominal constriction in mice. The antinociception is the percentage of inhibition which calculated from $(\mathrm{Vc}-\mathrm{Vt}) / \mathrm{Vc}^{*}$ 100, Where: Vc=Mean number of writhing in control animals, $\mathrm{Vt}=$ Mean number of writhing in test animals $(\mathrm{n}=6$ animals per group) 
Table 1: The antinociceptive effect of the $D$. scandens extract drug, diclofenac, and the combination determined from acetic acid-induced abdominal constriction in mice

\begin{tabular}{|c|c|c|c|}
\hline Treatment groups & Dose (mg/kg bw) & Number of writhes in $30 \mathrm{~min}$ & Inhibition (\%) \\
\hline Control (distilled water) & $0.1 \mathrm{ml} / \mathrm{kg} \mathrm{bw}$ & $72.2 \pm 2.8$ & - \\
\hline Aspirin & 50 & $15.6 \pm 2.5^{\mathrm{a} *}$ & 78.3 \\
\hline \multirow[t]{4}{*}{ D. scandens extract } & 1 & $68.0 \pm 2.0$ & 5.5 \\
\hline & 10 & $48.6 \pm 3.3^{a^{*}, b^{*}}$ & 32.5 \\
\hline & 100 & $38.6 \pm 2.2^{\mathrm{a}^{*}, \mathrm{~b}^{*}, \mathrm{c}^{*}}$ & 68.4 \\
\hline & 1000 & $12.0 \pm 0.6^{\mathrm{a}^{*}, \mathrm{~b}^{*}, \mathrm{c}^{*}, \mathrm{~d}^{*}}$ & 90.2 \\
\hline \multirow[t]{4}{*}{ Diclofenac } & 1 & $69.3 \pm 2.2$ & 3.7 \\
\hline & 50 & $36.3 \pm 2.6^{\mathrm{a}^{*}, \mathrm{e}^{*}, \mathrm{f}^{* *}}$ & 49.5 \\
\hline & 100 & $26.8 \pm 2.6^{\mathrm{a}^{*}, \mathrm{e}^{*}, \mathrm{f}^{*}, \mathrm{~g}^{* *}}$ & 62.7 \\
\hline & 150 & $14.0 \pm 1.4^{\mathrm{a}^{*}, \mathrm{e}^{*}, \mathrm{f}^{*}, \mathrm{~g}^{*}, \mathrm{~h}^{* *}}$ & 80.6 \\
\hline \multirow[t]{4}{*}{ Diclofenac/D. scandens extract (1/1.16) } & 8.2 & $63.7 \pm 2.9$ & 11.6 \\
\hline & 16.5 & $47.0 \pm 3.2^{\mathrm{a}^{*, i^{* * *}}}$ & 34.7 \\
\hline & 32.9 & $39.2 \pm 0.7^{a^{*}, i^{*}, j^{* *}}$ & 45.6 \\
\hline & 65.9 & $14.5 \pm 2.7^{\mathrm{a}^{*}, \mathrm{i}^{*}, \mathrm{j}^{*}, \mathrm{k}^{*}}$ & 79.9 \\
\hline
\end{tabular}

Thirty minutes after treatment, mice were injected i.p. with $0.75 \%(\mathrm{v} / \mathrm{v})$ acetic acid $(0.1 \mathrm{ml} / 10 \mathrm{~g} \mathrm{bw})$; the number of induced writhing was counted for $30 \mathrm{~min}$. Values are mean \pm SEM. SEM: Standard error of mean ( $n=6$ animals per each group). Analyzed by one-way ANOVA followed by Tukey's HSD test. ${ }^{*} \mathrm{p}<0.001,{ }^{* *} \mathrm{p}<0.05$. ${ }^{\mathrm{V}} \mathrm{VersuS}$ control group, ${ }^{\mathrm{b}, \mathrm{c}, \mathrm{d}}$ versus $D$. scandens extract drug at the concentration of 1,10 , and $100 \mathrm{mg} / \mathrm{kg}$ bw, respectively, e,f,gh versus diclofenac at the concentration of $1,10,50$, and $100 \mathrm{mg} / \mathrm{kg} \mathrm{bw}$, respectively, ${ }^{\mathrm{i}, \mathrm{j}, \mathrm{k}} \mathrm{versus}$ the combination at the concentration of $8.2,16.5$, and $32.9 \mathrm{mg} / \mathrm{kg}$ bw, respectively. D. scandens: Derris scandens, bw: Body weight, HSD: Honestly significantly different

Table 2: Theoretical and experimental $\mathrm{ED}_{50}$ values and the interaction index for the combinations of diclofenac with the $D_{\text {. }}$ scandens extract drug on acetic acid-induced abdominal constriction in mice

\begin{tabular}{|c|c|c|c|}
\hline Drugs & $\mathrm{ED}_{50}$ theoretical (mg/kg bw) & $\mathrm{ED}_{50}$ experimental (mg/kg bw) & Interaction index \\
\hline D. scandens extract drug & - & 35.5 & - \\
\hline Diclofenac & - & 30.4 & - \\
\hline Diclofenac/D. scandens extract drug (1/1.16) & 32.9 & 29.2 & $29.2 / 32.9=0.89$ \\
\hline
\end{tabular}

D. scandens: Derris scandens, $\mathrm{ED}_{50}$ : Effective dose $50 \%$

we found the synergistic analgesic interaction between the D. scandens extract drug and paracetamol with interaction index at 0.65 in the similar pain model [14].

The rationale underlying the practice of combining drugs in pain management is based on two considerations. First, combining drugs with different mechanisms may enhance the pain relief. Second, a single drug that provides satisfactory pain relief may cause at the same time, unacceptable side effects. Drug combination allows the reduction in the dose of the single component to achieve the same analgesic effect with reduced incidences of side-effects [15].

All of the NSAIDs appear to share at least one common mechanism, namely, inhibition of cyclooxygenase (COX) enzyme(s) which leads to a decrease in the synthesis of various prostaglandins and thromboxanes [16]. On the other hand, the mechanism of action of paracetamol includes inhibition of COX-3 in central nervous system, interaction with spinal $5-\mathrm{HT}_{3}$ receptors, and peripheral $\beta$-endorphin receptors $[17,18]$. Differences in the mechanism of action of paracetamol and NSAIDs make them a viable option for an effective combination.

Although the certain mechanism of action of the $D$. scandens extract drug is still unknown. Our study supports the hypothesis that the mechanism of analgesic action of D. scandens is likely to NSAIDs. The isoprenylated compounds, isolated from $D$. scandens stems, showed a high inhibitory effect on eicosanoid production for COX and 5-lipoxygenase [19]. Although the additivity analgesic interaction of the combination between the $D$. scandens extract drug and diclofenac could not significant reduce the dose of each drug alone, it may reduce incidences of side-effects. The major adverse event of $D$. scandens was gastrointestinal symptoms and showed no different relative risk with NSAIDs [20]. Diclofenac causes of high gastric or hepatic and renal toxicity [21].

The properties of a system that define a pharmacologic interaction between 2 drugs are likely complicated. The type of interaction between two drugs may be explained by altering the kinetics of each other or at various levels of drug action. The additivity interaction between diclofenac and the $D$. scandens extract drug provides new information about combination pain treatment and should be explored further in patients, especially with somatic and/or visceral pain.

\section{CONCLUSION}

The data of the present study demonstrated that diclofenac combined with the $D$. scandens extract drug produces an additivity analgesic effect. It is possible to suggest that the combinations of diclofenac and the extract will be effective for the clinical treatment of pain. In addition, it is demonstrated that the effect of the combinations diclofenac/the D. scandens extract is superior to that of either component. Therefore, these mixtures are a viable alternative to clinical pain management, especially because the low doses of the components may be a potential index of lower incidence of adverse effects.

\section{ACKNOWLEDGMENT}

The author would like to acknowledge the Research Institute and the Faculty of Science, Rangsit University, Thailand, for providing grants and facilities to carry out this study.

\section{REFERENCES}

1. Laupattarakasem P, Houghton PJ, Hoult JR, Itharat A. An evaluation of the activity related to inflammation of four plants used in Thailand to treat arthritis. J Ethnopharmacol 2003;85:207-15.

2. Ganapathy S, Josaphine JS, Thomas PS. Anti-inflammatory activity of Derris scandens. J Neurosci Res 2006;6:73-6.

3. Thailand National List of Essential Medicines; 2016. p. 244-5. Available from: http://www.drug.fda.moph.go.th:81/nlem.in.th. [Last retrieved on 2017 Feb 01].

4. Srimongkol Y, Warachit P, Chavalittumrong P, Sriwanthana B, Pairour R, Inthep C, et al. A study of the efficacy of Derris scandens (Roxb.) Benth. extract compared with diclofenac for the alleviation of low back pain. J Thai Tradit Altern Med 2007;5:17-23. 
5. Kuptniratsaikul V, Pinthong T, Bunjob M, Thanakhumtorn S, Chinswangwatanakul P, Thamlikitkul V. Efficacy and safety of Derris scandens Benth extracts in patients with knee osteoarthritis. J Altern Complement Med 2011;17:147-53.

6. The Government Public Relations Department. Promoting Thai Herbal Medicine and Health Behavior Change Program. Available from: http://www.thailand.prd.go.th/ewt news. php?nid=2141\&filename $=$ index. [Last retrieved on 2016 Feb 01].

7. Raffa RB. Pharmacology of oral combination analgesics: Rational therapy for pain. J Clin Pharm Ther 2001;26:257-64.

8. van Laar M, Pergolizzi JV Jr, Mellinghoff HU, Merchante IM, Nalamachu S, O'Brien J, et al. Pain treatment in arthritis-related pain: Beyond NSAIDs. Open Rheumatol J 2012;6:320-30.

9. Koster P, Anderson M, DeBeer EJ. Acetic acid analgesic screening. Fed Proc 1959;18:412-8.

10. Jain NK, Kulkarni SK. Antinociceptive and anti-inflammatory effects of Tanacetum parthenium L. extract in mice and rats. J Ethnopharmacol 1999;68:251-9.

11. Tallarida RJ. Drug synergism: Its detection and applications. J Pharmacol Exp Ther 2001;298:865-72.

12. Prabhu VV, Nalini G, Chidambaranathan N, Kisan SS. Evaluation of anti-inflammatory and analgesic activity of Tridax Procumbens. Linn against formalin, acetic acid and CFA induced pain models. Int J Pharm Pharm Sci 2011;3:126-30.

13. Benhouda A, Yahia M. Toxicity, analgesic and anti-pyretic activities of methanolic extract from Hyoscyamus Albus' leaves in albinos rats. Int J Pharm Pharm Sci 2014;6:121-7.

14. Punjanon T, Yingyong W, Untharin N. Analgesic Synergy Between Paracetamol and Derris scandens in Mice. Proceeding of RSU International Research Conference; 2017. p. 20-4.

15. Curatolo M, Sveticic G. Drug combinations in pain treatment: A review of the published evidence and a method for finding the optimal combination. Best Pract Res Clin Anaesthesiol 2002;16:507-19.

16. Vane JR. Inhibition of prostaglandin synthesis as a mechanism of action for aspirin-like drugs. Nat New Biol 1971;231:232-5.

17. Bonnefont J, Courade JP, Alloui A, Eschalier A. Antinociceptive mechanism of action of paracetamol. Drugs 2003;63:1-4.

18. Sprott H, Shen H, Gay S, Aeschlimann A. Acetaminophen may act through beta endorphin. Ann Rheum Dis 2005;64:1522.

19. Laupattarakasem P, Houghton PJ, Hoult JR. Anti-inflammatory isoflavonoids from the stems of Derris scandens. Planta Med 2004;70:496-501.

20. Puttarak P, Sawangjit R, Chaiyakunapruk N. Efficacy and safety of Derris scandens (Roxb.) Benth. for musculoskeletal pain treatment: A systematic review and meta-analysis of randomized controlled trials. J Ethnopharmacol 2016;194:316-323.

21. Modi CM, Mody SK, Patel HB, Dudhatra GB, Kumar A, Avale M. Toxicopathological overview of analgesic and anti-inflammatory drugs in animals. J Appl Pharm Sci 2014;2:149-57. 